\title{
Über den Gehalt des Kaninchen- und Hundeplasmas an peptolytischen Fermenten unter verschiedenen Bedingungen.
}

\author{
I. Mitteilung.
}

Von

Emil Abderhalden und Ladwig Pincussohn.

(Aus dem physiologischen Institut der tierärztlichen Hochschule, Berlin.)

(Der Redaktion zugegangen am 7. Juli 1909.)

In früheren Mitteilungen 1) war bereits hervorgehoben worden, daß Blutkörperchen, Blutplättchen und Plasma unter normalen Verhältnissen beim Pferde und Rinde einen verschiedenen Gehalt an peptolytischen Fermenten aufweisen, und vor allem ergab sich die wichtige Tatsache, daß dem Plasma dieser Tiere Fermente, die z. B. Glycyl-l-tyrosin zerlegen, ganz zu fehlen scheinen. Wir haben unsere Versuche auf andere Tierarten ausgedehnt und haben gefunden, daß Unterschiede bei verschiedenen Tierspezies vorhanden sind. So spaltet z. B. Plasma resp. Serum vom Kaninchen Glycyl-l-tyrosin sehr rasch in seine Komponenten, während Plasma vom Hund dieses Dipeptid gar nicht oder doch nur sehr langsam angreift. Wir haben nun versucht festzustellen, ob der Gehalt des Plasmas an peptolytischen Fermenten sich beeinflussen läßt. Wir injizierten Kaninchen und Hunden wiederholt teils Eiereiweiß, teils Pferde-

1) Emil Abderhalden und H. Deetjen, Über den Abbau einiger Polypeptide durch die Blutkörperchen des Pferdes. Diese Zeitschrift, Bd. LI, S. 334, 1907. - Weitere Studien über den Abbau einiger Polypeptide durch die roten Blutkörperchen und die Blutplättchen des Pferdeblutes. Ebenda, Bd. LIII, S. 280, 1907. - Emil Abderhalden und Berthold Oppler, Über das Verhalten einiger Polypeptide gegen Blutplasma und -serum vom Pferde. Ebenda, Bd. LIII, S. 294, 1907. Emil Abderhalden und Wilfred H. Manwaring, Über den Abbau einiger Polypeptide durch die roten Blutkörperchen und die Blutplättchen des Rinderblutes. Ebenda, Bd. LV, S. 377, 1908. - Emil Abderhalden und James S. McLester, Über das Verhalten einiger Polypeptide gegen das Plasma des Rinderblutes. Ebenda, Bd. LV, S. 371, 1908. 
serum und prüften dann nach einiger Zeit das Verhalten des Plasmas gegen einige Polypeptide. Zahlreiche Versuche ergaben, daß unzweifelhaft bei den mit artfremdem Eiweiß behandelten Tieren das Plasma einen höheren Gehalt an peptolytischen Fermenten aufwies oder, vorsichtiger ausgedrückt, Polypeptide rascher spaltete. Es kam dies besonders deutlich bei Versuchen mit Hundeblutplasma zum Ausdruck. Kaninchen sind für derartige Versuche weniger geeignet, weil ihr Plasma einmal an und für sich schon Polypeptide, z. B. Glycyl-l-tyrosin, spaltet, und es ferner nicht ganz leicht ist, Plasma resp. Serum zu gewinnen, das absolut frei von Blutfarbstoff ist. Die geringste Auflösung von roten Blutkörperchen macht derartige Untersuchungen unbrauchbar, weil die roten Blutkörperchen an und für sich viele Polypeptide lebhaft spalten. Diese Versuche sind vor mehr als Jahresfrist ausgeführt worden. Wir hielten mit der Veröffentlichung der Resultate zurück, um sie einesteils durch weitere Versuche $\mathrm{zu}$ sichern und andernteils nach mancherlei Richtungen zu erweitern. Der Befund, daß das Plasma von Hunden, denen bestimmte Eiweißarten parenteral zugeführt worden sind, z. B. Glycyl-l-tyrosin rasch spaltet, während das gleiche Dipeptid von normalem Hundeblutplasma bei gleicher Versuchsdauer kaum angegriffen wird, ist ohne Zweifel von einiger Bedeutung und weist vielleicht auf die Art hin, in der der Organismus sich gegen den Einfluß nicht arteigenen und noch nicht assimilierten Eiweißes schützt. ${ }^{1}$ ) Das beobachtete Auftreten von Fermenten ist vielleicht als Schutz zu deuten. Wir haben mit unseren Versuchen nur eine bestimmte Gruppe von Fermenten nachgewiesen, Fermente, die auf die einfacheren Abbaustufen der Eiweißstoffe eingestellt sind. Die erwähnten Beobachtungen machen es wahrscheinlich, daß auch Fermente auftreten, welche die höheren Abbauprodukte und die Proteine selbst angreifen. Weitere Versuche nach dieser Richtung sind in Angriff genommen.

Der Gang der Untersuchung war der gewöhnliche. In

1) Vgl. hierzu auch Ernst Heilner, Über die Wirkung großer Mengen artfremden Blutserums im Tierkörper nach Zufuhr per os und subkutan. Zeitschr. f. Biol., Bd. L, S. 26, 1907. 
jedem Falle wurde $1 \mathrm{~g}$ des Polypeptids mit $10 \mathrm{ccm}$ Plasma versetzt und die Lösung dann 3 Tage bei $37^{\circ}$ aufbewahrt. Nach erfolgter Enteiweißung mit Mastix und zum Teil mit Kaolin wurden dann die Spaltprodukte und etwa unverändertes Polypeptid isoliert. Da die Methoden der Isolierung schon mehrfach an dieser Stelle beschrieben worden sind, verzichten wir auf die Wiedergabe all der einzelnen Versuche und begnügen uns mit einer tabellarischen Wiedergabe der Resultate. Bemerkt sei noch, daß zur Verhinderung des Wachstums von Mikroorganismen Toluol angewandt wurde.

\section{Versuche mit Hundeplasma.}

a) Versuche mit Glycyl-l-tyrosin.

Der Hund erhielt am 20./III. 08

$$
\begin{array}{lr}
> & 31 . / \mathrm{III} . \\
> & 9 . / \mathrm{IV} . \\
& 20 . / \mathrm{IV} . \\
> & 11 . / \mathrm{V} . \\
> & 12 . / \mathrm{V} .
\end{array}
$$

$40 \mathrm{ccm}$ Pferdeserum subcutan

\begin{tabular}{|c|c|c|c|c|c|c|}
\hline \multirow{2}{*}{$\begin{array}{l}\text { Ver- } \\
\text { such }\end{array}$} & \multicolumn{3}{|c|}{$\begin{array}{c}\text { Plasma von normalen Tieren } \\
\text { Isoliert }\end{array}$} & \multicolumn{3}{|c|}{$\begin{array}{c}\text { Plasma von mit Eiereiwei } \\
\text { behandelten Tieren } \\
\text { Isoliert }\end{array}$} \\
\hline & $\begin{array}{l}\text { Glycin } \\
\text { in } g\end{array}$ & $\begin{array}{l}\text { Tyrosin } \\
\text { in } g\end{array}$ & $\begin{array}{l}\text { Glycyl-1-tyrosin } \\
\text { in } \mathrm{g}\end{array}$ & $\begin{array}{l}\text { Glycin } \\
\text { in } \mathrm{g}\end{array}$ & $\begin{array}{l}\text { Tyrosin } \\
\text { in } g\end{array}$ & $\begin{array}{l}\text { Glycyl-1-tyrosin } \\
\text { in } \mathrm{g}\end{array}$ \\
\hline 1. & 0 & 0 & 0,86 & 0,15 & 0,25 & 0,37 \\
\hline 2. & 0,05 & 0,02 & 0,75 & 0,2 & 0,35 & 0,1 \\
\hline & & & & \multicolumn{3}{|c|}{$\begin{array}{c}\text { Plasmavonmit Pferdeserum } \\
\text { behandelten Tieren }\end{array}$} \\
\hline 3. & 0 & 0 & 0,78 & 0,15 & 0,25 & 0,25 \\
\hline 4. & 0,1 & 0,15 & 0,56 & 0,18 & 0,28 & 0,26 \\
\hline 5. & - & - & - & 0 & 0,02 & 0,66 \\
\hline
\end{tabular}

$\begin{array}{lll}40 \text {, ’ } & \text {, } \\ 50 \text { > } & \text { > } \\ 50 \text { > } & \text { > }\end{array}$

Um 11 Uhr entblutet.

Ein zweiter Hund erhielt am 31./III. $0840 \mathrm{ccm}$ Eiereiweiß subcutan

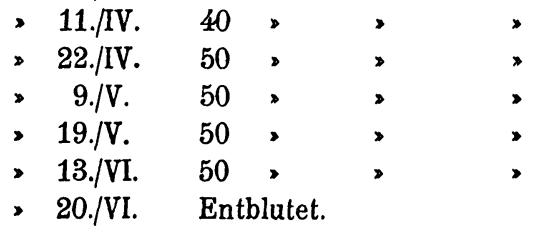


Peptolytische Fermente des Kaninchen- und Hundeplasmas. 203

b) Versuche mit dl-Leucyl-glycin.

Der Hund erhielt am 31./III. $0840 \mathrm{ccm}$ Eiereiweiß subcutan

\begin{tabular}{|c|c|c|c|c|}
\hline , 11./IV. & 40 & > & > & , \\
\hline 22./IV. & 50 & 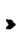 & , & 2 \\
\hline $9 . / \mathrm{V}$ & 50 & $\gg$ & , & 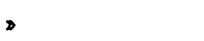 \\
\hline , 19./V. & 50 & > & , & $\triangleright$ \\
\hline 2./VI. & 50 & > & , & $>$ \\
\hline 4./VI. & 50 & s & $>$ & Entblutet. \\
\hline
\end{tabular}

\begin{tabular}{|c|c|c|c|c|c|c|}
\hline \multirow{2}{*}{$\begin{array}{l}\text { Ver- } \\
\text { such }\end{array}$} & \multicolumn{3}{|c|}{$\begin{array}{c}\text { Plasmavon normalen Tieren } \\
\text { Isoliert }\end{array}$} & \multicolumn{3}{|c|}{$\begin{array}{c}\text { Plasma von mit Eiereiweiß } \\
\text { behandelten Tieren } \\
\text { Isoliert }\end{array}$} \\
\hline & $\begin{array}{l}\text { Glycin } \\
\text { in } \mathrm{g}\end{array}$ & $\begin{array}{l}\text { Leucin } \\
\text { in } g\end{array}$ & $\begin{array}{l}\text { Leucyl-glycin } \\
\text { in } \mathbf{g}\end{array}$ & $\begin{array}{c}\text { Glycin } \\
\text { in } g\end{array}$ & $\begin{array}{l}\text { Leucin } \\
\text { in } \mathbf{g}\end{array}$ & $\begin{array}{l}\text { Leucyl-glycin } \\
\text { in } \mathbf{g}\end{array}$ \\
\hline 1. & 0 & 0 & 0,82 & 0,2 & 0,25 & 0,25 \\
\hline 2. & 0,05 & 0 & 0,73 & 0,12 & 0,18 & 0,30 \\
\hline 3. & 0,08 & 0,1 & 0,69 & 0,30 & 0,45 & 0 \\
\hline 4. & 0 & 0 & $0,7 \check{5}$ & 0 & 0 & 0,70 \\
\hline 5. & - & - & - & 0,12 & 0,20 & 0,45 \\
\hline
\end{tabular}

Die mit Diglycyl-glycin ausgeführten Versuche ergaben kein scharfes Resultat, weil das Plasma von normalen Hunden dieses Tripeptid auch schon spaltet. Isoliert wurden Glykokoll, Glycyl-glycin und unverändertes Tripeptid. Das Plasma derjenigen Versuchstiere, die vorbehandelt waren, ergab größere Miengen von Glykokoll, jedoch sind die Unterschiede nicht sehr erheblich. Hier muß unbedingt die Spaltung von bestimmten optisch aktiven Polypeptiden mit Hilfe der Polarisation verfolgt werden. Nur auf diesem Wege lassen sich Unterschiede in der Raschheit des Abbaus mit genügender Schärfe feststellen. Aus dem gleichen Grunde verzichten wir vorläufig auf die mit Plasma von normalen und vorbehandelten Kaninchen erhaltenen Resultate, weil auch hier die Ausschläge nicht genügend groß waren. Kaninchenplasma spaltet alle angewandten Polypeptide an und für sich. Bei Anwendung von Glycyl-l-tyrosin erfolgte fast durchwegs zuerst bei dem Plasma der vorbehandelten Tiere Tyrosinabscheidung, so daß auch hier ein Einfluß der Zufuhr von artfremdem Eiweiß vorzuliegen scheint. Jedenfalls haben 
204 A bderhalden u. Pincusso hn, Über Kaninchen-u. Hunderlasma. I.

wir in der Benutzung von Polypeptiden und ganz spezell von optisch aktiven Polypeptiden ein Mittel an der Hand, das uns gestattet, derartige Probleme in bestimmter Richtung zu verfolgen. Vor allen Dingen wird es mit Hilfe der optisclen Methode möglich sein, mit voller Schärfe zu entscheiden, ob der tierische Organismus nach parenteraler Zufuhr bestimnter Eiweißarten und von bestimmten Eiweißabbauprodukten und eventuell von synthetisch gewonnenen Polypeptiden Ferment $€$ an das Plasma abgibt, die für den zugeführten Körper spezifissh sind. 